\title{
Phylogenetic conservatism in the presence of a neurotensin-related hexapeptide in neurons of globus pallidus
}

\author{
ANTON REINER ${ }^{1}$ and ROBERT E. CARRAWAY2 \\ 'Department of Anatomy and Cell Biology, The University of Michigan, Ann Arbor, MI 48109 and 2Physiology Department. \\ University of Massachusetts Medical School, Worcester, MA 01605 (U.S.A.)
}

(Accepted March 26th, 1985)

Key words: neurotensin - LANT-6 — pallidal neurons - amniotes — basal ganglia immunohistochemistry - evolution - coexistence

\begin{abstract}
The vast majority of the pallidal neurons of the hamster, pigeon, caiman and turtle basal telencephalon were positively labeled by an antiserum against LANT-6, a neurotensin-like hexapeptide. In sharks also, LANT-6-positive neurons were observed in the apparent equivalent of the globus pallidus. These results, which imply the coexistence of a LANT-6-like peptide with gamma-aminobutyric acid (GABA) in pallidal neurons, suggest that a LANT-6-like peptide may be an important and evolutionarily conserved neurotransmitter/neuromodulator in pallidal neurons.
\end{abstract}

LANT-6 is a neurotensin-related hexapeptide that was discovered in large amounts in extracts of chicken intestine during the isolation and characterization of the avian neurotensin-like tridecapeptide corresponding to mammalian neurotensin 5,6 . This hexapeptide contains the same C-terminal tetrapeptide sequence as neurotensin and has been termed LANT -6 because of the presence of lysine and asparagine as the $\mathrm{N}$-terminal amino acid residues 7 . Substantial levels of LANT- 6 are also present in the avian brain and a transmitter function for LANT-6 is suggested by its presence in synaptosomal fractions of the avian brain 9 . The role of LANT-6 is apparently distinct from that of neurotensin since LANT-6 shows different receptor binding properties and has different peripheral effects than neurotensin ${ }^{16.22}$. Immunohistochemical, radioimmunoassay (RIA) and chromatographic studies have suggested that a LANT-6-like peptide may be present in the nervous system in members of a wide variety of vertebrate groups 7.8 .10 .17 . For example, LANT-6 was recently found in retinal ganglion cells and their central terminals in turtles ${ }^{10}$ and similar observations have been made in goldfish, frogs, chickens, pigeons and rats (ref. 17 and A. Reiner, unpublished observations).
We report here that a LANT-6-like peptide is present in pallidal neurons of the basal ganglia in birds. reptiles and mammals and is also present in the spiny dogfish shark in telencephalic neurons that appear to be equivalent to amniote pallidal neurons. These results suggest that pallidal neurons in a wide variety of vertebrate groups may use a LANT-6-like peptide as a transmitter/modulator substance. The present data also show that a LANT-6-like peptide has been conserved in pallidal neurons since the beginnings of the evolution of amniotes and that a LANT-6-like peptide may have been present in pallidal neurons as early as the divergence of bony and cartilaginous fish.

The subjects of the present study were golden hamsters (Mesocricetus auratus). white Carneaux pigeons (Columba livia), red-eared turtles (Pseudemys scripta), juvenile caiman (Caiman crocodilus) and spiny dogfish sharks (Squalus acanthias). All animals were deeply anesthetized (birds, turtles and hamsters with ketamine, caiman with somlethol and spiny dogfish with MS222) and perfused through the left ventricle with $6 \%$ dextran in phosphate buffer $(\mathrm{pH} 7.4)$ followed by $4 \%$ paraformaldehyde in phosphate buffer ( $\mathrm{pH} 7.4)$, except in the case of pigeons, for which the paraformaldehyde-lysine-periodate

Correspondence: A. Reiner. Department of Anatomy and Cell Biology, The University of Michigan, Ann Arbor. MI 48109. U.S.A 

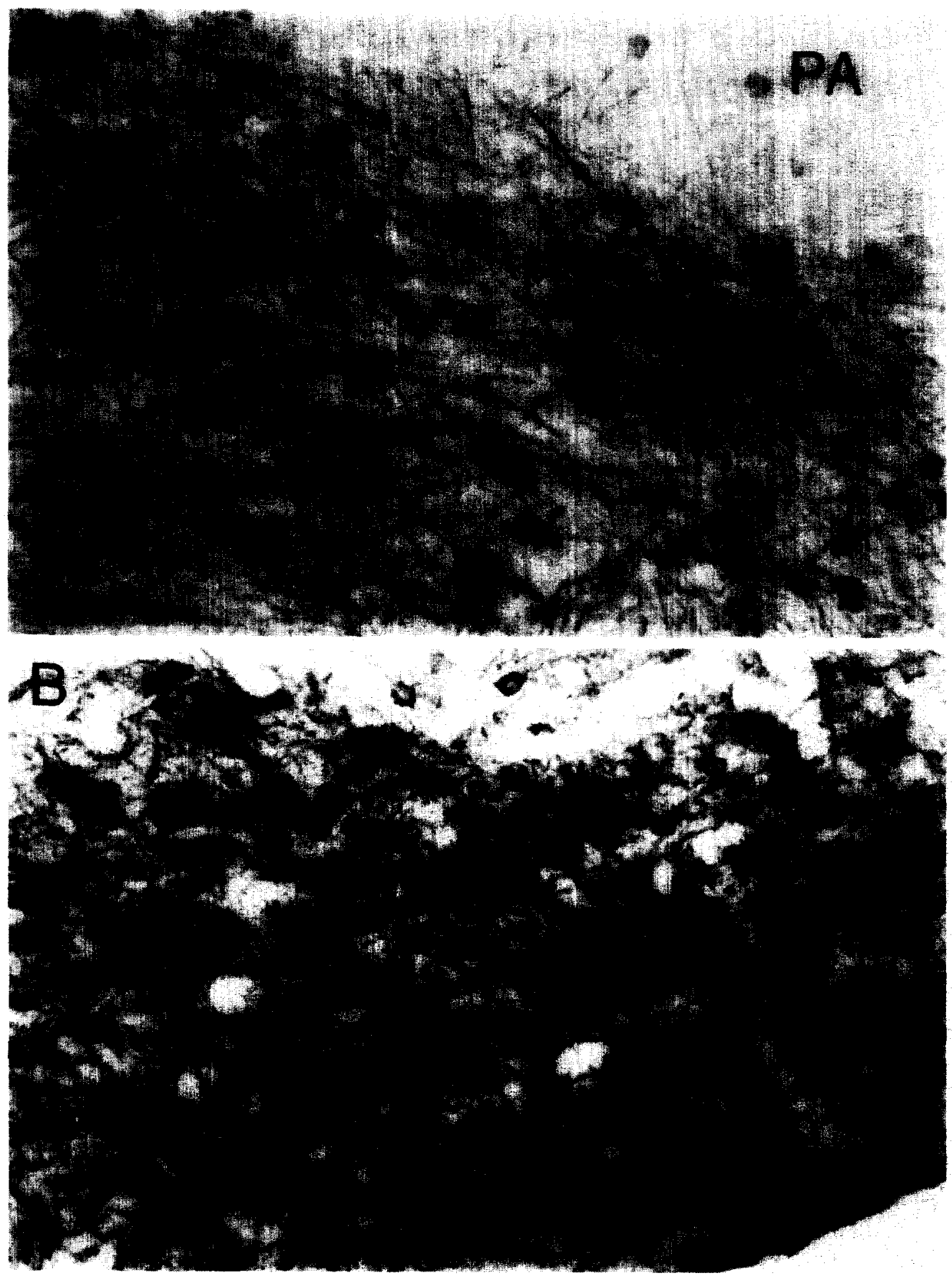

Fig. 1. LANT-6-positive neurons in the pallidal cell groups of the basal ganglia of pigeon (A) and turtle (B). Both photomicrographs are of transverse sections processed according to the peroxidase-antiperoxidase procedure. Lateral is to the right and dorsal toward the top in both photomicrographs. Portions of both the pallidal cell group (paleostriatum primitivum, PP) and the striatal cell group (paleostriatum augmentatum. PA) of pigeon are shown in $\mathrm{A}$. The field of view in B is restricted nearly entirely to the globus pallidus of turtle. In both photomicrographs numerous large neurons $(25-40 \mu \mathrm{m})$ are heavily labeled for LANT-6. Labeled processes, presumably of pallidal neurons, are also abundant in the pallidal field in both pigeon and turtle. A few labeled neurons are evident in $\mathrm{PA}$ in the upper right of A. Scale bar, $100 \mu$ in 
fixative was used ${ }^{20}$. Brains were subsequently sectioned frozen at $40 \mu \mathrm{m}$ on a sliding microtome and sections through the forebrain and midbrain were processed according to the peroxidase-antiperoxidase (PAP) immunohistochemical procedure, as described previously ${ }^{4.28-30}$, using an antiserum towards LANT-6 (TG-22) that was shown not to crossreact with neurotensin ${ }^{9}$. A 1:1000 primary antiserum dilution was used in the present study and staining described in this paper could be blocked with $10-50 \mu \mathrm{M}$ synthetic LANT-6.

Several previous studies have used hodological and histochemical criteria to identify the globus pallidus-equivalent cell group in birds and reptiles ${ }^{2-4}$. 14,25-29. In brief, the ventrolateral wall of the telencephalon in birds and reptiles contains two major cell populations, a more dorsally situated 'striatal' cell group (which displays the same hodological and histochemical characteristics as the mammalian striatum) and a more ventrocaudally situated 'pallidal' cell group (comparable to the mammalian globus pallidus). In pigeons and turtles, the pallidal cell group is cytoarchitectonically a relatively distinct cell field containing many large neurons. Using the antiserum toward LANT-6, the vast majority of the neurons in this 'pallidal' field, including numerous large neurons $(25-40 \mu \mathrm{m})$, were heavily labeled (Fig. 1). Thick processes arising from these neurons could be observed to ramify within the 'pallidal' field. Pallidal neurons were not, however, labeled by antisera specific for neurotensin (such as antiserum HC-8, ref. $8)$. Within the ventrolateral telencephalon, LANT6-positive neurons were not restricted to the pallidal cell field. A number of additional large as well as smaller LANT-6-positive neurons were observed in the ventral paleostriatum (comparable to the ventral pallidum of mammals), the olfactory tubercle and the 'striatum' of pigeon and turtle. In the case of these latter cell fields, however, the LANT-6-positive neurons constituted a much lesser percentage of the total number of neurons than in the case of the 'pallidal' cell field. Consistent with the presence of a LANT-6like peptide in pallidal and ventral pallidal neurons in pigeons and turtles, LANT-6-positive fibers were observed in the mesencephalic targets of these neurons: the ventral tegmental area (which receives input from the ventral pallidum) and the nucleus tegmentipedunculopontinus, pars compacta (TPc) (which re- ceives pallidal input) of pigeons and the ventral tegmental area and the substantia nigra of turtles. In crocodilians, the 'pallidal' cell field is less distinct cytoarchitectonically than in turtles and pigeons ${ }^{2-4}$. Nonetheless, large LANT-6-positive neurons were observed in the ventrocaudal portions of the largecelled part of the ventrolateral area (VLAlc), which is known to be the source of the 'pallidal' projections of the caiman basal ganglia ${ }^{3}$. As in pigeons and turtles, LANT-6-positive neurons were also observed in the olfactory tubercle and in the 'striatum' (in caiman comprising the small-celled part of the ventrolateral area, VLAsc, and the dorsolateral VLAlc). Although their distribution will not be described here, LANT-6-containing neurons were not restricted to the ventrolateral telencephalon of birds and reptiles but were widespread and numerous throughout the brain.

LANT-6-positive labeling of numerous neurons in the globus pallidus was also demonstrated in hamster, although the staining was lighter than in birds and reptiles (Fig. 2A). The lighter staining may stem from an interspecies variation in the structure of the peptide. Using RIA and high performance liquid chromatography (HPLC), Carraway et al. ${ }^{9}$ demonstrated the presence of LANT-6-related material in rat brain, but the low concentrations measured using the TG-22 antiserum suggest that the mammalian counterpart differs slightly from the avian form. Minamino et al. ${ }^{21}$ have recently identified a new peptide, Neuromedin $\mathrm{N}$, which was obtained from porcine spinal cord and which is identical to LANT-6 in amino acid sequence except for the substitution of isoleucine for asparagine. If Neuromedin $\mathrm{N}$ is the mammalian form of LANT-6, it may be this peptide that is present in hamsters in neurons labeled by TG-22. In hamsters, in addition to numerous large neurons labeled throughout the globus pallidus and the entopeduncular nucleus, numerous large and small LANT-6-like immunoreactivity-containing neurons were also observed in the olfactory tubercle and ventral pallidum.

Northcutt et al. ${ }^{23}$ have recently identified the basal ganglia of spiny dogfish shark based on immunohistochemical comparisons of the shark telencephalon to the telencephala of birds, reptiles and mammals. The medially situated ventrolateral periventricular region (VLP) was identified as the 'striatum' based on the presence of numerous substance P-positive neu- 

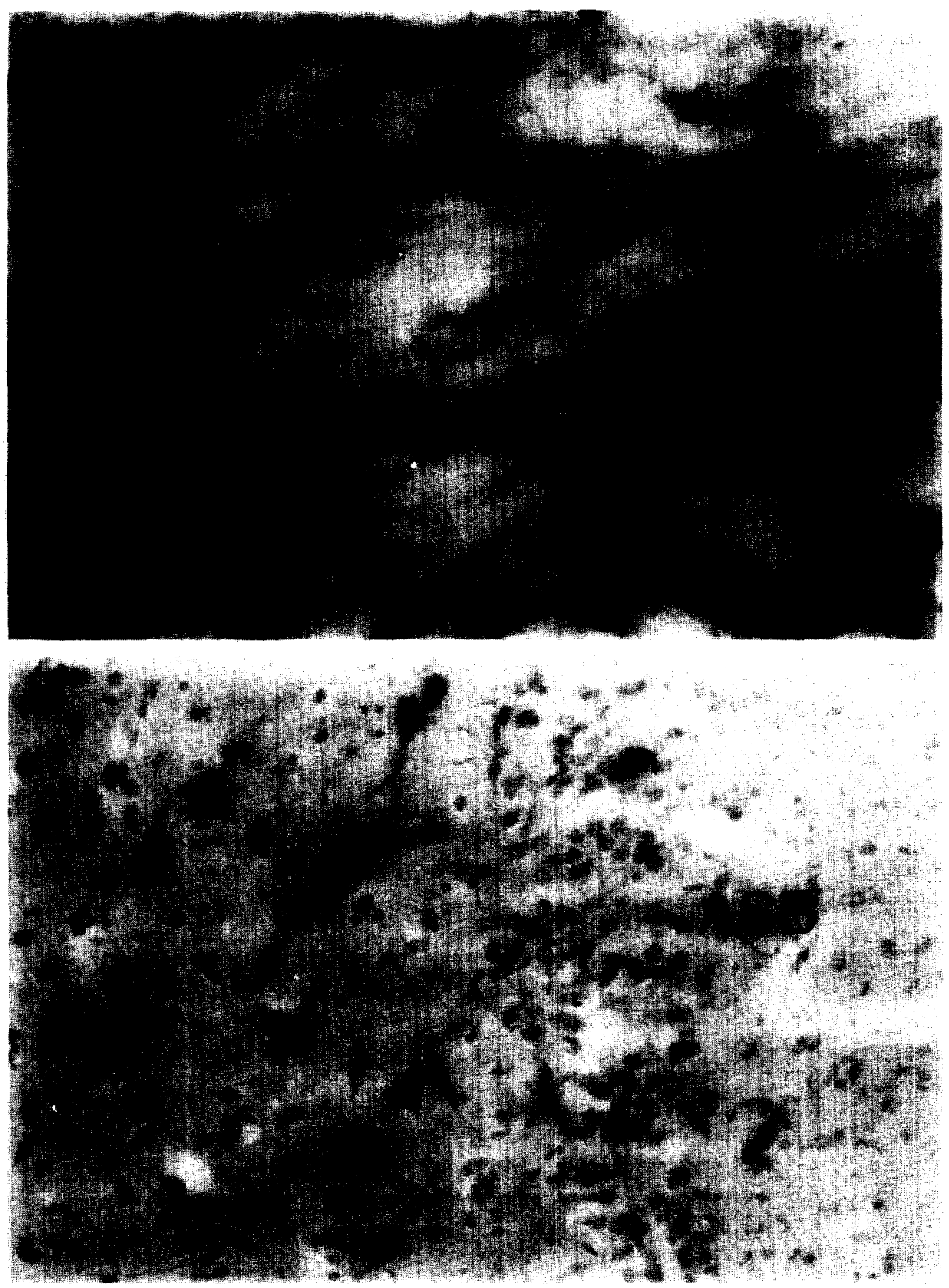

Fig. 2. LANT-6-positive pallidal neurons in the pallidal cell groups in hamster (A) and shark (B). Both photomicrographs ate of transverse sections processed according to the peroxidase-antiperoxidase procedure. Lateral is to the right in both photomicrographs and dorsal toward the top. The field of view in $\mathrm{A}$ is restricted nearly entirely to the globus pallidus and numerous labeled neurons are evident. The labeled neurons, although smaller than the pallidal neurons in birds and reptiles, include the largest neurons present in the globus pallidus of the hamster. The field of view in B includes the medially situated ventrolateral periventricular area (VLP) and the more laterally situated area superficialis basalis (ASB) of the shark telencephalon. The VLP is comparable to the amniote striatum. The ASB consists of a plate of cells parallel to the pial surface and the region immediately $(100-200 \mathrm{~km})$ lateral and medial to the cell plate. The ASB appears to be comparable to the amniote pallidum. The LANT-6-positive neurons were numerous in and near the cell plate of ASB, as can be seen in B. Scale bar. $100 \mathrm{~km}$ 
rons and enkephalin-positive neurons and on the presence of tyrosine hydroxylase-positive fibers and serotonin-positive fibers. A more laterally situated ventrolateral cell field, the area superficialis basalis (ASB), was identified as the 'pallidum' based on the high concentration of substance P-positive fibers and enkephalin-positive fibers and on the paucity of tyrosine hydroxylase-positive fibers. In the present study, antiserum TG-22 heavily labeled numerous large neurons in and along the edges of the cell plate of ASB throughout its dorsoventral extent (Fig. 2B). These neurons were morphologically distinct from the bipolar neurons that appeared to be the most numerous cell type in the cell plate and were generally similar in size and morphology to amniote pallidal neurons. Based on their location as well as their morphological and histochemical characteristics, these neurons appear to be the pallidal neurons of the spiny dogfish basal ganglia. Data concerning the efferent projections of these neurons would provide important further evidence regarding this possibility.

Since pallidal neurons are generally thought to use GABA as their transmitter ${ }^{19}$, the present results provide suggestive evidence for the co-occurrence of a LANT-6-like peptide and GABA in pallidal neurons. Although numerous peptides have been identified in striatal neurons, previous immunohistochemical studies have not unequivocally demonstrated the presence of any peptides, including neurotensin, in pallidal neurons $13,15,18,25,31$. Antisera raised by one of us towards neurotensin (e.g. HC-8) also do not label 'pallidal' neurons in birds and reptiles (Reiner and Carraway, unpublished observations). In mammals, fibers containing neurotensin-like immunoreactivity have, however, been observed in such projection targets of globus pallidus and the ventral pallidum ${ }^{11}$ as the dopaminergic neuron-rich midbrain cell groups, the substantia nigra pars compacta and the ventral tegmental area ${ }^{13,31}$. In addition, high levels of receptors for neurotensin have been observed in these areas in mammals ${ }^{24}$. In pigeons also, high levels of neurotensin-like peptide(s) and receptors for neurotensin are present in the ventral tegmental area and the TPc, the avian equivalent of the substantia nigra pars compacta (S.E. Brauth, C. A. Kitt, A. Reiner, B. Jones and R. Quirion, in preparation). As noted above, LANT-6-positive fibers are also clearly present in these midbrain pallidal and ventral pallidal projection targets in birds and reptiles. The possibility therefore exists that in all amniotes both a neurotensin-like peptide and a LANT-6-like peptide are present in the same terminals in these midbrain cell groups, terminals that arise from pallidal neurons. If this is the case, it is unclear why the LANT-6-like material but not neurotensin should be detectable in pallidal neurons by immunohistochemistry. One possible explanation is that the kinetics of biosynthetic processing for these two peptides are different in perikarya than in terminals.

The present findings suggest that LANT- 6 may be released from pallidal terminals and have an important influence on such pallidal projection targets as the dopaminergic neurons of the midbrain. Although little information is available concerning the electrophysiological effects of LANT-6, neurotensin is known to excite midbrain dopaminergic neurons and promote increased dopamine turnover ${ }^{1,22}$. The present results raise the possibility that LANT-6 may have similar effects and may be employed by pallidal neurons in influencing dopaminergic neurons. To further examine this possibility, it will be important to determine whether distinct LANT-6 receptors are present on midbrain dopaminergic neurons. Although the presence of a LANT-6-like substance in pallidal neurons raises the possibility that non-tegmental projection targets of the pallidum also receive a LANT-6-containing input, LANT-6-positive labeling of terminals in these non-tegmental areas was equivocal in the present study.

The apparent conservation of a LANT-6-like peptide in pallidal neurons during evolution is an additional striking finding of the present study. The presence of a LANT-6-like substance in 'pallidal' neurons in birds, reptiles and mammals suggests that a LANT-6-containing pallidal cell group was a constituent of the basal ganglia as early as the early reptiles that were the common ancestors of modern amniotes ${ }^{12}$. Previous studies have shown that many of the neurotransmitter/neuropeptide-specific cell populations composing the amniote 'striatum' must also have been present in these ancestral reptiles 25 and that some of these 'striatal' populations must have also been present in the vertebrate telencephalon as early as the divergence of bony and cartilaginous fish (since they are present in modern cartilaginous fish $)^{23}$. The present results suggest that LANT-6-pos- 
itive pallidal neurons (as well as pallidal neurons themselves) may also have appeared in the telencephalon prior to the divergence of cartilaginous and bony fish and have been retained in the evolutionary lines leading to modern amniotes and modern cartilaginous fish. In recent studies, prominent large LANT-6-positive neurons that may be pallidal neurons were observed in the ventrolateral wall of the telencephalon in frogs (Reiner, unpublished observations) and lungfish (Reiner and Northcutt, unpublished observations). Further study, however, is required to determine if these neurons in spiny dogfish shark, frogs and lungfish have 'pallidal' connections.

In summary, the present findings demonstrate that

1 Andrade, R. and Aghajanian, G. K., Neurotensin selectively activates dopaminergic neurons in the substantia nigra, Soc. Neurosci. Abstr., 7 (1981) 573.

2 Brauth, S. E., Enkephalin-like immunoreactivity within the telencephalon of the reptile Caiman crocodilus, Neuroscience, 11 (1984) 345-358.

3 Brauth, S. E. and Kitt, C. A., The paleostriatal system of Caiman crocodilus, J. comp. Neurol., 189 (1980) 437-465.

4 Brauth, S. E., Reiner, A., Kitt, C. A. and Karten, H. J., The substance P-containing striato-tegmental path in reptiles: an immunohistochemical study, J. comp. Neurol., 219 (1983) 305-327.

5 Carraway, R. E. and Bhatnagar, Y. M., Immunochemical characterization of neurotensin-like peptides in chicken, Peptides, 1 (1980) 159-165.

6 Carraway, R. E. and Bhatnagar, Y. M., Isolation, structure and biological activity of chicken intestinal neurotensin, Peptides, 1 (1980) 167-194.

7 Carraway, R. E. and Ferris, C. F., Isolation, biological and chemical characterization and synthesis of neurotensin-related hexapeptide from chicken intestine, J. biol. Chem., 258 (1983) 2475-2479.

8 Carraway, R. E., Ruane, S. E. and Kim, H. R., Distribution and immunochemical character of neurotensin-like material in representative vertebrates and invertebrates: apparent conservation of the $\mathrm{COOH}$-terminal region during evolution, Peptides, 1 (1982) 115-123.

9 Carraway, R. E., Ruane, S. E. and Ritsema, R., Radioimmunoassay for $\mathrm{Lys}^{8}, \mathrm{Asn}^{9}$ neurotensin 8-13: tissue and subcellular distribution of immunoreactivity in chickens, Peptides, 4 (1983) 111-116.

10 Eldred, W., Isayama, T., Reiner, A. and Carraway, R. E., Peptidergic ganglion cells in the turtle retina, Soc. Neurosci. Abstr., 10 (1984) 458.

11 Graybiel, A. M. and Ragsdale, C. F. Jr., The fiber connections of the basal ganglia. In M. Cuenod, G. W. Kreutzberg and F. E. Bloom (Eds.), Development and Chemical Specificity of Neurons, Elsevier, Amsterdam, 1979, pp. 239-283.

12 Hopson, J. A., Paleoneurology. In C. Gans, R. G. Northcutt and P. Ulinski (Eds.), Biology of the Reptilia, Vol. 9, pallidal neurons in members of both ancient and more recently evolved vertebrate classes stain positively for LANT-6, thereby suggesting that this peptide may play an important and evolutionary conserved role in the motor functions of the basal ganglia.

We wish to thank Dr. S. E. Brauth for supplying us with caiman brain material, Dr. R. G. Northcutt for supplying us with spiny dogfish brain material, and Dr. M. G. Honig for helpful comments on the manuscript. This research was supported by NS-19620 (A.R.) and AM 28565 and AM 28557 (R.E.C.).

Neurology A, Academic Press, New York, 1979, pp. 39-146.

13 Jennes, L., Stumpf, W. E. and Kalivas, P. W., Neurotensin: topographical distribution in rat brain by immunohistochemistry, J. comp. Neurol., 210 (1982) 211-224.

14 Karten, H. J. and Dubbeldam, J. L., The organization and projections of the paleostriatal complex in the pigeon ( $\mathrm{Co}$ lumba livia), J. comp. Neurol., 148 (1973) 437-465.

15 Khachaturian, H., Lewis, M. E., Hollt, V. and Watson, S $\mathrm{J}$., Telencephalic enkephalinergic systems in the rat brain, J. Neurosci., 3 (1983) 844-855.

16 Kitabgi, P., Checkler, F. and Vincent, J. P., Comparison of some biological properties of neurotensin and its natural analogue LANT-6, Europ. J. Pharmacol., 99 (1984) $357-360$

17 Li, H. B., Eldred, W. D., Carraway, R. E. and Dowling, J. E., Localization of LANT-6-like immunoreactivity within ganglion and amacrine cells in vertebrate retina, Invest. Ophthalmol. Vis. Sci. Suppl., 25 (1984) 284.

18 Ljungdahl, A., Hökfelt, T and Nilsson, G., Distribution of substance P-like immunoreactivity in the central nervous system of the rat. I. Cell bodies and nerve terminals, Neuroscience, 3 (1978) 861-944.

19 McGeer, P. L., Eccles, J. C. and McGeer, E. G., Molecular Neurobiology of the Mammalian Brain, Plenum Press. New York, 1978.

20 McLean, I. W. and Nakane, P. K., Periodate-lysine-paraformaldehyde fixative. A new fixative for immunoelectron microscopy, J. Histochem. Cytochem., 22 (1974) 1077-1083.

21 Minamino, N., Kangawa, K. and Matsuo, H., Neuromedin $\mathrm{N}$ : a novel neurotensin-like peptide identified in porcine spinal cord, Biochem. Biophys. Res. Commun., 122 (1984) 542-549.

22 Nemeroff, C. B. and Prange, A. J. Jr., Neurotensin, a Brain and Gastrointestinal Peptide, Ann. N.Y. Acad. Sci., Vol. 400,1982

23 Northcutt, R. G., Reiner, A. and Karten, H. J., The basal ganglia of spiny dogfish: an immunohistochemical study, Anat. Rec., 208 (1984) 128A.

24 Quirion, R., Gaudreau, R., St.-Pierre, S., Rioux, F. and 
Pert, C. B., Autoradiographic distribution of $\left[{ }^{3} \mathrm{H}\right]-$ neurotensin receptors in rat brain: visualization with tritium-sensitive film, Peptides, 3 (1982) 757-763.

25 Reiner, A., Brauth, S. E. and Karten, H. J., Evolution of the amniote basal ganglia, Trends Neurosci., 7 (1984) $320-326$

26 Reiner, A., Brauth, S. E., Kitt, C. A. and Karten, H. J., Basal ganglionic pathways to the tectum: studies in reptiles, J. comp. Neurol., 193 (1980) 565-589.

27 Reiner. A., Brecha, N. C. and Karten, H. J., Basal ganglia pathways to the tectum: the afferent and efferent connections of the lateral spiriform nucleus of pigeons, J. comp. Neurol., 208 (1982) 16-36.

28 Reiner. A., Davis, B. M., Brecha, N. C. and Karten, H. J.,
The distribution of enkephalin-like immunoreactivity in the telencephalon of the adult and developing domestic chicken, J. comp. Neurol., 228 (1984) 245-262.

29 Reiner, A., Karten, H. J. and Solina, A. R., Substance P: localization within paleostriatal-tegmental pathways in the pigeon, Neuroscience, 9 (1983) 61-85.

30 Reiner, A., Krause, J. E.. Keyser, K. T., Eldred, W. D. and McKelvy, J. F., The distribution of substance $P$ in turtle nervous system: a radioimmunoassay and immunohistochemical study, J. comp. Neurol., 226 (1984) 50-75.

31 Uhl, G. R., Goodman, R. R. and Snyder. S. H., Neurotensin-containing cell bodies, fibers and nerve terminals in the brainstem of the rat. Immunohistochemical mapping, Brain Research, 167 (1979) 77-91. 